\title{
Adenylate-cyclase activity in platelets of patients with obsessive-compulsive disorder
}

\author{
This article was published in the following Dove Press journal: \\ Neuropsychiatric Disease and Treatment \\ 30 June 2009 \\ Number of times this article has been viewed
}

\author{
D Marazziti \\ S Baroni \\ L Palego \\ I Masala \\ G Consoli \\ M Catena Dell'Osso \\ G Giannaccini \\ A Lucacchini \\ Dipartimento di Psichiatria, \\ Neurobiologia, Farmacologia e \\ Biotecnologie, Università di Pisa, \\ Pisa, Italy
}

Correspondence: Donatella Marazziti Dipartimento di Psichiatria, Neurobiologia, Farmacologia e Biotecnologie, University of Pisa, Via Roma 67, 56100 Pisa, Italy $\mathrm{Tel}+39050835412$

Fax+390502158I

Email dmarazzi@psico.med.unipi.it

\begin{abstract}
Although the main biological hypothesis on the pathophysiology of obsessive-compulsive disorder (OCD) is centered on the serotonin system, indications are available that other neurotransmitters, and even second messengers, particularly the cyclic adenosine monophosphate (cAMP) signaling, may be involved, though effective data are few. Therefore, the aim of the present study was to evaluate and compare the basal and isoprenaline (ISO)-stimulated velocity of adenylate-cyclase (AC) in human platelet membranes of patients with OCD and healthy control subjects. The results showed that the basal and ISO-stimulated AC activity, as well as the dose-response curves of ISO by using agonist concentrations ranging between $0.1 \mathrm{nM}$ and $10 \mu \mathrm{M}$, were not different in the two groups. However, OCD patients showed lower $\mathrm{EC}_{50}$ and higher $\mathrm{E}_{\max }$ values than healthy subjects. These findings suggest the presence of supersensitive $\beta$-adrenergic receptors in platelets of OCD patients.
\end{abstract}

Keywords: obsessive-compulsive disorder, norepinephrine, second messengers, adenylatecyclase, platelets, isoprenaline, $\beta$-adrenergic receptors

\section{Introduction}

The most consistent hypothesis on the pathophysiology of obsessive-compulsive disorder (OCD) is focused on the serotonin (5-HT) system and, to a lesser extent, on dopamine (DA). ${ }^{1}$ However, few indications are available on the involvement of other neurotransmitters, such as norepinephrine (NE), peptides and, more recently, glutammate. ${ }^{2-4}$ For NE, decreased levels of tiramine, a precursor of catecholamines, and of homovallinic acid, one of their metabolites, in the cerebrospinal fluid of OCD patients have been reported. ${ }^{5}$ Other support for a role of NE in OCD has been provided by the blunted growth hormone response to clonidine, an $\alpha_{2}$-adrenoreceptor antagonist, which would suggest hypersensitive presynaptic or hyposensitive postsynaptic $\alpha_{2}$ receptors, ${ }^{6}$ but a negative finding has also been reported. ${ }^{2}$ Similar controversies are present in the literature on the direct evaluation of the binding parameters of $\alpha_{2}$-adrenoreceptors in platelets. In fact, when labeled by $\left[{ }^{3} \mathrm{H}\right]$ rauwolscine, they showed a similar density in OCD patients and control subjects, ${ }^{7}$ while $\left[{ }^{3} \mathrm{H}\right]$ clonidine revealed a greater density of $\alpha_{2}$-adrenoreceptors in OCD patients. ${ }^{2}$ The possible role of $\alpha_{2}$-adrenoreceptors is indirectly supported by the evidence that mirtazapine, an $\alpha_{2}$-adrenoreceptors antagonist, may reduce the onset of citalopram response in OCD patients. ${ }^{8}$

Blood platelets represent a reliable, peripheral model of presynaptic serotonergic neurons; in particular, they possess a 5-HT reuptake transporter similar to that present in the brain which has been deeply investigated in different psychiatric disorders including 
OCD. ${ }^{9-10}$ Besides the 5-HT transporter, platelets carry 5-HT1A and 5-HT2 receptors, but also structures belonging to the catecholamine systems, such as the DA transporter and $\alpha$-and $\beta$-adrenergic receptors. ${ }^{11}$ More recently, much interest has been devoted to intracellular mechanisms following receptor activation and there is a preliminary evidence for the involvement of cyclic adenosine monophosphate (cAMP) signaling in OCD, as shown by the lower protein kinase A (PKA) activity. ${ }^{12-13}$

In the present study, we aimed to explore and compare the basal adenylate cyclase (AC) activity in platelets of OCD patients and healthy control subjects, and that after stimulation by isoprenaline (ISO), a synthetic catecholamine which behaves as a $\beta_{1}-/ \beta_{2}$-adrenergic receptor agonist, in both the absence and the presence of $\alpha$ - and $\beta$-adrenoreceptor antagonists.

\section{Methods}

\section{Subjects}

Twenty patients ( 10 men and 10 women, aged between 22 and 31 years; mean \pm SD: $24.1 \pm 6.5$ ), recruited at the outpatient unit of the "Clinica Psichiatrica, Dipartimento di Psichiatria, Neurobiologia, Farmacologia e Biotecnologie" at Pisa University, were included in the study. All met DSM IV-TR criteria for OCD, were not currently depressed, or had any history of mood disorders or any other comorbid conditions. Diagnoses were made by experienced psychiatrists, following the Structured Clinical Interview for DSM IV (SCID). ${ }^{14}$ No patients had ever taken psychotropic drugs in the past, except three who had taken benzodiazepines 1 year previously and one who had undergone supporting psychotherapy.

The subjects' age (mean $\pm \mathrm{SD}$ ) at the onset of OC symptoms was $17 \pm 5$ years and the duration (mean \pm SD) of the disorder was $5 \pm 1$ years.

The severity of OC symptoms was evaluated by means of the Yale Brown Obsessive-Compulsive Scale (Y-BOCS). ${ }^{15}$ The total score (mean $\pm \mathrm{SD}$ ) was $26.4 \pm 6.3$ (range: 25 to 40 ); the obsession subtotal score (mean \pm SD) was $14.2 \pm 4.5$ (range: 13 to 20 ); the compulsion subtotal score (mean $\pm \mathrm{SD}$ ) was $14.5 \pm 4.9$ (range: 12 to 20 ). The most commonly reported obsessions by the Y-BOCS Check-List were "contamination" (66.7\%), "order and symmetry" (25.5\%) and "others" $(23.3 \%)$ comprising the need to remember certain things, the fear of saying certain things, the fear of being inexact, intrusive images, meaningless sounds or words or musical themes, fortunate/unfortunate numbers, and meaningful colors. The most common compulsions were cleaning (53.3\%), checking (53.3\%), and repetition (53.3\%). The degree of insight (mean \pm SD) was $1.5 \pm 1.5$ (range: 0 to 4 ). Eight patients only had one obsession and/or compulsion, while the remaining 12 had more than one.

The severity of depression was rated by means of the Hamilton Rating Scale for depression (HRSD): ${ }^{16}$ the total score (mean $\pm \mathrm{SD}$ ) was $4 \pm 1$ and $3 \pm 2$ in, respectively, OCD patients and healthy controls.

Twenty healthy volunteers (10 men and 10 women, aged between 21 and 32 years, mean age \pm SD: $24.2 \pm 7.1$ ) were selected for this study according to the following criteria: all subjects were without familiar or personal history of major psychiatric disorders, as assessed by the SCID, and had no current medical complaints and were physically healthy, as ascertained by their medical history and physical examination. No woman of both groups took contraceptive pills.

All subjects gave their written informed consent to participate in the study which was approved by the Ethics Committee at Pisa University.

\section{Chemicals}

The radio-labelled compounds $\left[{ }^{32} \mathrm{P}\right] \alpha-\mathrm{ATP}$ (specific activity: $30 \mathrm{Ci} / \mathrm{mmol}$ ) and $\left[{ }^{3} \mathrm{H}\right]$ cAMP (specific activity: $27 \mathrm{Ci} / \mathrm{mmol}$ ) were purchased from Perkin Elmer Life Science (Boston, MA, USA). Creatine kinase and creatine phosphate were obtained from Roche Molecular Biochemicals (Mannheim, Germany). All other reagents were from Sigma-Aldrich Chemical Co. (Milan, Italy) and of the highest grade available.

\section{Methods}

Thirty $\mathrm{mL}$ of blood were collected from fasting subjects between 8.00 and $10.00 \mathrm{AM}$ to avoid circadian rhythm interference. Samples were immediately put into Falcon tubes containing sodium citrate anticoagulant (1:6 dilution), composed by $2.2 \%$ sodium citrate, $1.2 \%$ citric acid, and gently mixed. Platelet-rich plasma (PRP) was obtained by blood low-speed centrifugation at $200 \times \mathrm{g}$ for $20 \mathrm{~min}$ at room temperature. The PRP was then centrifuged at $2000 \times \mathrm{g}$ for $15 \mathrm{~min}$ at room temperature to precipitate platelets.

\section{Adenylate cyclase assay}

Platelets were washed once in 40 to $50 \mathrm{~mL}$ isotonic solution, $0.9 \% \mathrm{NaCl}$, by centrifugation at $15,000 \times \mathrm{g}$ for $15 \mathrm{~min}$ at $4{ }^{\circ} \mathrm{C}$. The resulting pellet was resuspended in a strongly hypotonic buffer containing $5 \mathrm{mM}$ Hepes- $\mathrm{NaOH}$, pH 7.4 at $25^{\circ} \mathrm{C}, 1 \mathrm{mM}$ EGTA and protease inhibitors (bacitracine $20 \mathrm{mg} / 100 \mathrm{~mL}$; benzamidine $16 \mathrm{mg} / 100 \mathrm{~mL}$, soybean trypsine inhibitor, $2 \mathrm{mg} / 100 \mathrm{~mL}$ ). Samples, kept on ice, were then homogenized by ultraturrax for 5 to $10 \mathrm{sec}$. After a 10- to 15-min incubation 
at $0{ }^{\circ} \mathrm{C}$ to remove endogenous compounds, samples were then centrifuged at $40,000 \times \mathrm{g}$ at $4{ }^{\circ} \mathrm{C}$ for $15 \mathrm{~min}$. The final pellet was frozen in liquid nitrogen and stored until assay, performed within no more than 2 weeks. On the day of assay, membrane pellets were thawed and suspended in $10 \mathrm{mM}$ Hepes buffer $\mathrm{pH} 7.4$, containing $1 \mathrm{mM}$ EGTA, to obtain a protein concentration of about 0.8 to $1.8 \mathrm{mg} / \mathrm{mL}$ : protein estimation was performed by means of the Bradford Bio-Rad kit, ${ }^{17}$ using $\gamma$-globulin as the standard. AC activity was measured in the reaction mixture, as described previously, ${ }^{18}$ with slight modifications, such as the presence in the mix buffer of $0.33 \mathrm{mM}$ EGTA, $0.005 \mathrm{mM}$ pargyline and the use of GTP at the concentration of $0.01 \mathrm{mM}$.

Basal enzyme activity was also evaluated in the absence or presence of various concentrations $(0.1 \mathrm{nM}$ to $10 \mu \mathrm{M})$ (-)ISO. Some experiments were performed by adding the $\beta$ antagonist propranolol $(1 \mu \mathrm{M})$ and the $\alpha_{2}$ antagonist rauwolscine $(10 \mu \mathrm{M})$. The reaction was started by the addition of $50 \mu \mathrm{L}$ of membrane suspension and carried out by incubating samples for $15 \mathrm{~min}$ at $30^{\circ} \mathrm{C}$ in a final assay volume of $150 \mu \mathrm{L}$. $\left[{ }^{32} \mathrm{P}\right] \alpha-\mathrm{AMPc}$ and $\left[{ }^{3} \mathrm{H}\right] \mathrm{AMPc}$ were further purified through a double-step Dowex-Alumina chromatography. ${ }^{13}$

\section{Data analysis}

All experiments performed herein were carried out in duplicate and presented as mean \pm SEM. Statistical significance was preset at $\mathrm{p}=0.05$. Data analysis and statistics were performed by GraphPad Software Inc., version 3.00, San Diego, CA, USA. The equation of Salomon ${ }^{12}$ was used to evaluate $\mathrm{AC}$ activity (pmol cAMP/min/mg protein). Concentrationresponse curves of ISO on basal AC were analyzed in order to estimate $\mathrm{EC}_{50}$ (potency, concentration of drug causing $50 \%$ of the maximal effect on enzyme activity, $\mathrm{nM}$ ) and $\mathrm{E}_{\max }$, (efficacy, maximal inhibition, \%) values. Data were shown as percentage (\%) of basal AC activity in the presence of ISO vs basal AC activity without the agonist (considered to be $100 \%$ ). Two-tailed paired (within group) or unpaired $t$-tests (between group) were used to compare platelet $\mathrm{AC}$ velocities or ISO dose-response parameters in the two groups.

\section{Results}

As shown in Table 1, the platelet basal AC activity was similar in OCD patients and healthy subjects. The addition of $10 \mu \mathrm{M}$ ISO enhanced significantly $(\mathrm{p}<0.05)$ platelet basal $\mathrm{AC}$ in both groups, without intergroup differences.

The different concentrations of ISO led to dose-response curves with $\mathrm{EC}_{50}$ and $\mathrm{E}_{\max }$ values (mean $\pm \mathrm{SEM}$ ), different in the two groups: OCD patients showed significantly lower
Table I Basal and I0 $\mu$ M ISO-stimulated adenylate cyclase activity in platelet membranes from healthy subjects and OCD patients

\begin{tabular}{lll}
\hline & Basal AC & + ISO I0 $\mu \mathrm{M}$ \\
\hline Healthy subjects & $14.00 \pm 1.72$ & $20.61 \pm 2.50$ \\
OCD patients & $13.60 \pm 1.59$ & $22.99 \pm 3.48$ \\
\hline
\end{tabular}

Note: Data are presented as mean \pm SEM of $n$ experiments each performed in duplicate.

Abbreviation: ISO, isoprenaline.

$(\mathrm{t}=4.78, \mathrm{p}=0.01)$ mean $\mathrm{EC}_{50}$ and higher $(\mathrm{t}=6.46, \mathrm{p}=0.01)$ mean $\mathrm{E}_{\max }$ than healthy subjects (Table 2, Figure 1).

In previous work, carried out in intact human platelets, the ISO stimulation was generally determined in the presence of the $\alpha$-adrenergic antagonist phentolamine to avoid platelet $\alpha_{2}$ inhibition of $\mathrm{AC}$ at the tested agonist concentrations. ${ }^{19-21}$ In the present study, we observed a stimulatory response after ISO in all subjects even without $\alpha$-antagonists. Figure 2 shows the dose-response curves of ISO alone and in the presence of $10 \mu \mathrm{M}$ rauwolscine, $1 \mu \mathrm{M}$ propranolol, and both antagonists. The addition of rauwolscine provoked a small leftward shift of the curve, whereas the addition of propranolol, a $\beta$-blocker, abolished the stimulation and revealed a weak ISO-mediated inhibition of AC at its higher concentrations ( 1 to $10 \mu \mathrm{M}$ ). The concomitant addition of ISO, rauwolscine and propranolol led to a partial AC stimulation by ISO $\left(\mathrm{EC}_{50}\right.$ and $\mathrm{E}_{\max }$ of about $2.5 \mu \mathrm{M}$ and $25 \%$, respectively), while displaying a dose-response curve shifted towards the right.

In the presence of rauwolscine the $\mathrm{ISO} \mathrm{EC}_{50}$ (mean $\pm \mathrm{SEM}$, $\mathrm{n}=3$ ) was $68.67 \pm 26.91 \mathrm{nM}$ and the $\mathrm{E}_{\max }$ was $161.3 \pm 8.57 \%$. In the same experiments without rauwolscine, the ISO $\mathrm{EC}_{50}$ (mean $\pm \mathrm{SEM}, \mathrm{n}=3$ ) was $88.33 \pm 16.59 \mathrm{nM}$ and the $\mathrm{E}_{\max }$ $147.7 \pm 1.45 \%$, not statistically different.

No correlation between biochemical parameters and clinical characteristics of the disorder was detected.

\section{Discussion}

The main findings of the present study were the following. First, we did not detect any difference in the basal AC activity

Table 2 ISO stimulation parameters measured in platelet membranes of healthy subjects and OCD patients

\begin{tabular}{lll}
\hline & $\mathrm{EC}_{50}(\mathbf{n M})$ & $\mathbf{E}_{\max }(\%)$ \\
\hline Healthy subjects & $85.62 \pm 18.82$ & $151.70 \pm 4.40$ \\
OCD patients & $53.80 \pm 23.26^{*}$ & $177.40 \pm 9.5 I^{* *}$ \\
\hline
\end{tabular}

Notes: Data are presented as mean \pm SEM of 3 experiments each performed in duplicate.

*significant, $\mathrm{t}=4.78, \mathrm{p}=0.01$.

$* *$ significant, $\mathrm{t}=6.46, \mathrm{p}=0.0 \mathrm{I}$.

Abbreviation: ISO, isoprenaline. 


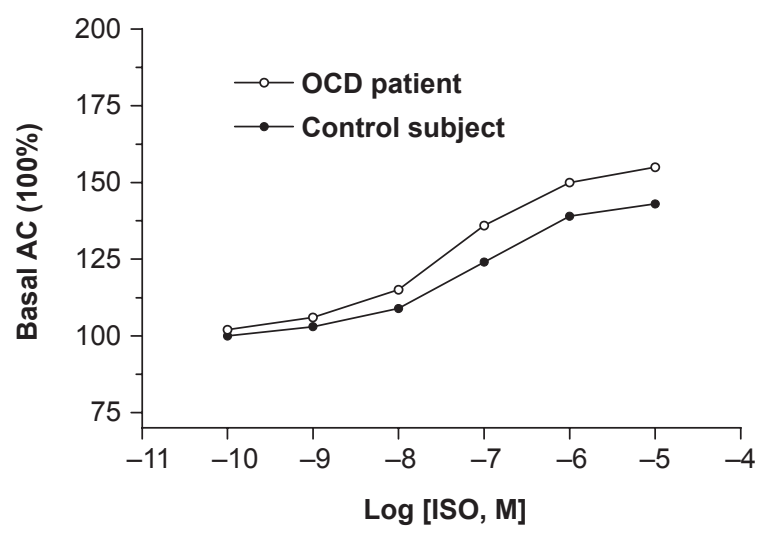

Figure I Isoprenaline dose-response curve in one OCD patient and control subject. Abbreviation: ISO, isoprenaline

in platelet membranes of healthy subjects and OCD patients. The addition of $10 \mu \mathrm{M}$ ISO to platelet membranes provoked a significant stimulation of the enzyme activity of the same magnitude in the two groups. When different concentrations of ISO were used, the dose-response curve showed a significant decrease of the agonist $\mathrm{EC}_{50}$ and increase of $\mathrm{E}_{\max }$ values in OCD patients, as compared with those of control subjects. The $\beta$-blocking compound (-)propranolol $(1 \mu \mathrm{M})$ removed the ISO response, while revealing also a weak degree of inhibition of AC at ISO concentrations $>1 \mu \mathrm{M}$. In the presence of rauwolscine $10 \mu \mathrm{M}$, the ISO-stimulating response showed a shift of EC50 of about 1.5-fold. Previous studies in whole platelets showed that the presence of $\alpha$-antagonists, such as phentolamine, can provoke the ISO-stimulating response. ${ }^{22}$ In our study, carried out in platelets membranes and in the presence of an optimal mix of reaction, we observed a significant stimulation via ISO, even in the absence of the $\alpha$-antagonists. OCD patients and healthy controls were compared by using a lower range of concentration of the agonist and by eliminating the highest concentrations of ISO, when the activation of the inhibiting $\alpha_{2}$ receptors was detected. These findings suggests that, under our experimental conditions, there is an inhibitory component of ISO effect on platelet AC, due to the agonist interaction with $\alpha_{2}$-receptors, at its higher concentrations $(>1 \mu \mathrm{M})$.

These results suggest the presence of a condition of supersensitive $\beta$-receptors in platelets of OCD patients that, perhaps, could reflect (or provoke) alterations of the intracellular signaling system mediated by the cAMP and of the related kinases. This is consistent with recent findings showing a decreased activity of PKA in OCD patients. ${ }^{23}$

The concomitant evidence of increased PKC activity, triggered by the hydrolysis of phosphatidylinositol $(4,5)$ bisphosphate (PI), in patients suggest that, perhaps, this

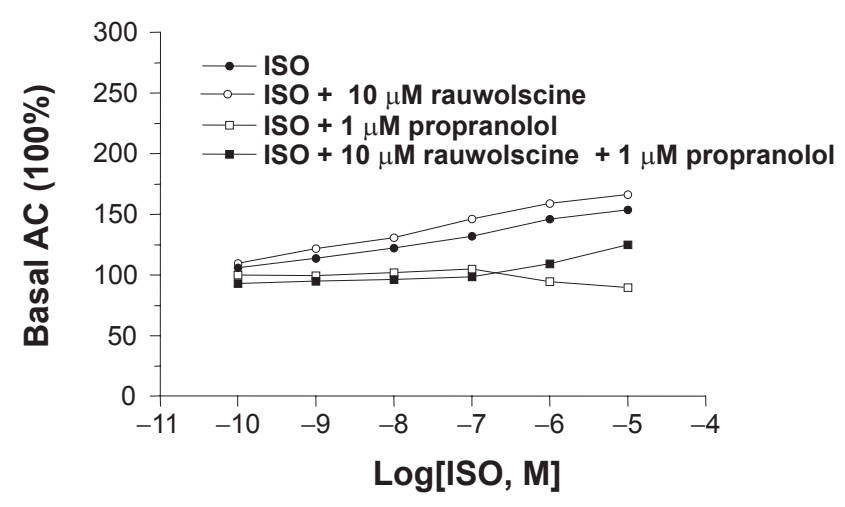

Figure 2 Dose-response curve of isoprenaline alone and in the presence of rauwolscine, propanolol and both the compounds.

Abbreviation: ISO, isoprenaline

condition might be characterized by an imbalance between the two main second-messenger pathways (cAMP and PI), with a prevalence of the second, given the cross-talk between the two main second messengers at the level of different effectors. ${ }^{12}$

In conclusion, the results of the present study suggest that abnormal second messenger pathways in OCD may be also related to cathecolamine system disturbances, which might open new therapeutic strategies especially in resistant patients who do not respond to serotonergic medications.

\section{Disclosures}

The authors disclose no conflicts of interest.

\section{References}

1. Westenberg HG, Fineberg NA, Denys D. Neurobiology of obsessivecompulsive disorder: serotonin and beyond. CNS Spectr. 2007;2(3): 14-27.

2. Lee MA, Cameron OG, Gurguis GN, et al. Alpha 2-adrenoreceptor status in obsessive-compulsive disorder. Biol Psychiatry. 1990;27(10):1083-1093.

3. McDougle CJ, Barr LC, Goodman WK, Price LH. Possible role of neuropeptides in obsessive compulsive disorder. Psychoneuroendocrinology. 1999;24(1):1-24.

4. Bhattacharyya S, Chakraborty K. Glutamatergic dysfunction - newer targets for anti-obsessional drugs. Recent Patents CNS Drug Discov. 2007;2(1):47-55.

5. Leckman JF, Goodman WK, Anderson GM, et al. Cerebrospinal fluid biogenic amines in obsessive compulsive disorder, Tourette's syndrome, and healthy controls. Neuropsychopharmacology. 1995;12(1):73-86.

6. Hollander E, DeCaria C, Nitescu A, et al. Noradrenergic function in obsessive-compulsive disorder: behavioral and neuroendocrine responses to clonidine and comparison to healthy controls. Psychiatry Res. 1991;37(2):161-177.

7. Marazziti D, Baroni S, Masala I, et al. Platelet alpha2-adrenoreceptors in obsessive-compulsive disorder. Neuropsychobiology. 2004;49(2): 81-83.

8. Pallanti S, Quercioli L, Bruscoli M. Response acceleration with mirtazapine augmentation of citalopram in obsessive-compulsive disorder patients without comorbid depression: a pilot study. J Clin Psychiatry. 2004;65(10):1394-1399. 
9. Lesch KP, Wolozin BL, Murphy DL, Riederer P. Primary structure of the human platelet serotonin uptake: identity with the brain serotonin transporter. J Neurochem. 1993;60:2319-2322.

10. Marazziti D, Rossi A, Gemignani A, et al. Decreased platelet ${ }^{3} \mathrm{H}$-paroxetine binding in obsessive-compulsive patients. Neuropsychobiology. 1996;34:184-187.

11. Stahl S.M. Essential Psychopharmacology: Neuroscientific Basic and Practical Applications. Cambridge University Press, 2008.

12. Marazziti D, Perez J, Cassano GB. Is obsessive-compulsive disorder caused by a second-messenger imbalance? CNS Spectr. 2001; 6(3):206-209.

13. Johnson RA, Alvarez R, Salomon Y. Determination of adenylyl cyclase catalytic activity using single and double column procedures. Meth Enzymol. 1994;238:31-56.

14. First MB, Spitzer RL, Gibbon M, Williams JBW. Structured Clinical interview for DSM-IV Axis I disorders - Patient Edition (SCID-I/P, Version 2.0). New York, NY: Biometrics Research Department, New York State Psychiatric Institute; 1995.

15. Goodman WK, Price LH, Rasmussen RA, et al. The Yale-Brown Obsessive Compulsive Scale: I. Development Use and Reliability. Arch Gen Psychiatry. 1989;46:1006-1011.

16. Hamilton M. A rating scale for depression. J Neurol Neurosurg Psychiatry. 1960;23:56-62.
17. Fanger BO. Adaptation of the Bradford protein assay to membrane-bound proteins by solubilizing in glucopyranoside detergents. Anal Biochemistry. 1987;162(1):11-17.

18. Dell'Osso L, Carmassi C, Palego L, et al. Serotonin-mediated cyclic AMP inhibitory pathway in platelets of patients affected by panic disorder. Neuropsychobiology. 2004;50(1):28-36.

19. Kerry R, Scrutton MC. Platelet beta-adrenoceptors. Br J Pharmacol. 1983;79(3):681-691.

20. Winther K, Klysner R, Geisler A, Andersen PH. Characterization of human platelet beta-adrenoceptors. Thromb Res. 1985;40(6): 757-767.

21. Hedman C, Winther K, Knudsen JB. Platelet function in classic migraine during attack-free periods. Acta Neurol Scand. 1988;78(4):271-277.

22. Hollister AS, FitzGerald GA, Nadeau JH, Robertson D. Acute reduction in human platelet alpha 2-adrenoreceptor affinity for agonist by endogenous and exogenous catecholamines. J Clin Invest. 1983;72(4): 1498-1505.

23. Perez J, Tardito D, Ravizza L, Racagni G, Mori S, Maina G. Altered cAMP-dependent protein kinase $\mathrm{A}$ in platelets of patients with obsessive-compulsive disorder. Am J Psychiatry. 2000;157(2) 284-286.
Neuropsychiatric Disease and Treatment

\section{Publish your work in this journal}

Neuropsychiatric Disease and Treatment is an international, peerreviewed journal of clinical therapeutics and pharmacology focusing on concise rapid reporting of clinical or pre-clinical studies on a range of neuropsychiatric and neurological disorders. This journal is indexed on PubMed Central, the 'PsycINFO' database and CAS, and is the official

\section{Dovepress}

journal of The International Neuropsychiatric Association (INA). The manuscript management system is completely online and includes a very quick and fair peer-review system, which is all easy to use. Visit http://www.dovepress.com/testimonials.php to read real quotes from published authors. 